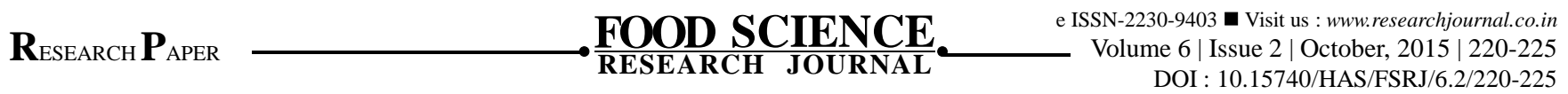

\title{
General status and effect of bael and nutrition intervention on sign, symptoms and physical activity of type 2 diabeties patient
}

\author{
UtTARA Singh
}

\begin{abstract}
The one hundred twenty non-insulin dependent diabetic selected subjects from Punjab Agricultural University and Civil Hospital of Ludhiana were divided into four groups viz., group I, II, III and IV having thirty subjects each. The subjects of group I was not given any treatment. The nutrition education was given for three months after fifteen days interval to the subjects of group II, III and IV through individual and group contact and gain in nutrition knowledge was assessed after the study. General information, diabetic information and dietary pattern of the subjects were recorded. Significant improvements were seen in physical activity, sleeping pattern and dietary pattern of the subjects of group II, III and IV after study. Therefore, it can be reported from the results that supplementation of bael (Aegle marmelos L.) leaf, pulp and seed powder along with nutrition counseling significantly improved the general status of the diabetic patients.
\end{abstract}

Key Words : Bael leaf, Pulp and seed powder, Diabetes

How to cite this article : Singh, Uttara (2015). General status and effect of bael and nutrition intervention on sign, symptoms and physical activity of type 2 diabeties patient. Food Sci. Res. J., 6(2): 220-225. 